\title{
Development of a Mobile e-Learning Platform on Physics Using Augmented Reality Technology
}

\author{
https://doi.org/10.3991/ijim.v16i05.26961 \\ Yevgeniya A. Daineko( ${ }^{(凶)}$, Dana D. Tsoy, Aigerim M. Seitnur, Madina T. Ipalakova \\ International Information Technology University, Almaty, Kazakhstan \\ y.daineko@iitu.edu.kz
}

\begin{abstract}
The rapid changes caused by the pandemic worldwide has affected every sphere of our lives and accelerated the digitalization process. With the constant increase in the computing power of tablets and smartphones, new opportunities for their use in trade, industry, medicine, and education have emerged. Our current transition to Industrialization 4.0, supported mainly by mobile technologies, has helped preserve this condition. The authors have researched this area to implement the project, studied various approaches and experiences during COVID-19. The authors attempted to observe relevant world experience and hypothesize that mobile devices have a high potential for forming a new effective learning model when adequately integrated. The experience of researchers from different countries is highlighted, in which the authors share their observations and discoveries made after the world moved to distance learning in spring 2020 . This article focuses on the experience of developing a mobile application for distance physics learning in higher and secondary educational institutions using augmented reality technology. The article consistently describes how the authors have made through the development process, including the background research and testing the product among users. The paper gives paper the project implementation process, the rationale for the used tools, and a description of the various stages of development. A student survey supports the proposed hypothesis, and the article also includes an analysis of the responses. The paper highlights the advantage of using digital educational tools, which have shown significant importance during the unplanned closure of schools and universities due to the coronavirus. Our future work lies in the improvements of research design and application optimization.
\end{abstract}

Keywords-mobile e-learning platform, mobile application, augmented reality, Unity3D, physics

\section{$1 \quad$ Introduction}

In this work, an attempt is made to investigate and evaluate the potential of new technologies to compensate for knowledge that has traditionally been obtained through direct interaction. The global pandemic of 2020 has brought many processes online around the globe, and this has evolved into one of the most severe issues, with mixed consequences that we still have to deal with. This situation has had the most significant 
impact on areas where live interaction is critical: the education, service sector, event, and entertainment industries.

However, the situation in the educational sphere is the most crucial because it involves the young generation, which is in the formation stage, and thus ineffective decisions can harm future development. In addition, it is essential to remember about the psychological state of pupils and students, who, despite the high level of proficiency in technology, even at a young age [1], yet are not always able to control the situation entirely. Even adults are not always able to select the best solutions. The unplanned closure of schools and universities due to the Covid-19 pandemic has had clear implications on education worldwide and has accelerated the adoption of digital and mobile technologies in the education system.

Many research papers that attempt to observe and track mental and general health issues have been published since spring 2020, which was challenging for everyone. Davis et al. explore distance learning from the perspective of teachers' mental health and how it affects them. It is shown that it causes mental distress for teachers and parents [2].

Karakose et al. [18] discuss other problems revealed during the lockdown, and they related to many aspects of our lives. The research results show that most state structures were not ready for these changes, reflected in COVID-19 phobia and conflicts within families and workplaces.

Despite these complexities, as is discussed in [3], students were motivated and tended to pass all the assignments on time. Another positive outcome is that students got more time to rest though limited with impersonal communication.

The use of mobile technology during the pandemic has become the most organic solution due to its prevalence and ease of use. According to [4], the number of smartphones worldwide is increasing from year to year. Mobile phones rose to prominence and became a panacea for many educational institutions. On the one hand, life changes brought about by social distancing and self-isolation, and the development and spread of mobile technologies have resulted in new teaching methods. Traditional education failed, and it was necessary to rethink the educational paradigm focusing on digital and mobile technologies.

One of the disadvantages of distance learning is that students cannot gain practical skills, for example, within physics courses, because there is no direct access to laboratory facilities for conducting experiments. Therefore, we decided to create a program that combines the approach of challenging games and allows performing practical tasks, studying physical processes. Traditionally, practical teaching methods are problem-solving, laboratory works, and home experiments. Students develop the ability to apply theoretical knowledge, measurement skills, and mathematical data processing. The practical skills for performing experiments, measuring, recording, and processing the results are of fundamental importance for mastering this course. When there is no access to actual equipment during distance learning, it is more expedient to use virtual laboratories and simulators with virtual and augmented reality to form the necessary practical skills by students.

Today, almost all students use mobile devices for educational purposes. A transformation of students' attitudes towards electronic devices occurs-from considering gadgets as means of communication and devices for consuming game and music 
content and communicating on social networks to using them as an element of online education.

This paper attempts to investigate how mobile technologies can change the learning process. To get a complete picture of the current situation and the active use of new methods in education in the era of sustainable development and industrialization 4.0, an analysis of relevant world experience in this area was made. The advantages and disadvantages of the approach are considered. Based on the research, an algorithm for developing the software package was developed in the "Instruments" and "Implementation" sections. The application development process and the tools that were involved are presented. After development, a survey was done among students who evaluated the application itself and its functionality. The "Results and Evaluation" section reflects the project evaluation results and analysis. Future work is displayed in the "Conclusion" section, and it describes the following steps to work on the project.

Thus, this article considers how to make the assimilation of physical laws more effective, accessible, and interesting for students using mobile devices and virtual and augmented reality technologies. This work will reveal the potential properties of mobile technologies and mixed reality in studying physics courses in an accessible and fascinating format.

\section{Related works}

The learning process with mobile devices such as laptops, mobile phones, and tablets has become a new research topic worldwide, while their application in everyday life has long been a reality. Several studies are devoted to using mobile devices in the educational process and the efficacy of the methodology and practice of using gadgets for educational purposes [5-7].

Liashenko and Tereshchuk [8], in their work, analyze the possibilities of introducing mobile learning technologies into school practice as means of building information and digital competencies of students. The authors argue that the low level of mobile education implementation in school practice is due to a lack of methodological support and an incorrect description of how to use mobile applications in specific didactic situations. On the Plickers mobile application example, the possibilities of such an approach in teaching physics are demonstrated [9].

Salnyk [10] studied the use of mobile technologies in teaching physics as well. In particular, the possibilities of mobile applications and sensors of mobile devices are considered as measuring instruments for conducting physical experiments. The author argues that using mobile device sensors in a virtual-oriented environment significantly expands their functionality. This opens up the possibility of designing and developing low-cost laboratories that can engage physics lessons in and out of the classroom.

The study of the application of mobile augmented reality to support teaching and learning physics in high school is discussed by Fojtik [11]. He explored the didactic capabilities of this technology using a system of web and mobile applications. The results of the author's research undoubtedly show that mobile augmented reality can increase students' motivation and interest while successfully supporting the learning and teaching of physics in high school. In addition, the author considers the use of 
mobile learning technologies for special needs children. The paper describes the experience of their implementation in the framework of inclusive education.

An exciting overview of online tools for creating mobile applications, such as App Inventor, Thunkable, AppsGeyser, AppyBuilder, Infinity Monkeys, is presented in the article by Voštinár [12]. With these tools, any teacher can create their mobile app without prior programming skills. The author highlighted the advantages and disadvantages of using these online tools. There is an example of a mobile app designed for each online tool designed for training.

If we consider foreign experience from the perspective of the teaching methods effectiveness, then an exciting example of an article is presented by Rochmah et al. [13]. This study develops a mobile app to integrate augmented reality (AR) features into puzzle-like games. To determine the effectiveness of the proposed platform, experiments were carried out to assess the impact on academic performance and students' motivation in two groups: experimental (based on AR) and control (traditional approach). The results showed that the AR-based group scored significantly more points $(\mathrm{p}<0.05)$ than the control group, which increases the value of the new approach to teaching natural sciences at the primary school level. However, the AR-based group also showed a relative decrease in confidence, suggesting further research is needed to understand the impact of AR technology on students' motivation.

Other researchers, such as Tavares et al. [14], believe that modern technology offers many ways to improve teaching and learning, which, in turn, contribute to the development of tools for educational activities both inside and outside classrooms. Many educational programs that apply augmented reality (AR) technology are widely used to provide additional educational materials. This article describes the potential and problems of using GeoGebra AR in mathematical research, allowing students to view 3D geometric objects to understand their structure better and verifies the feasibility of its use based on the experimental results [15].

In education, augmented reality makes learning more exciting and engaging. The problems of performing laboratory and practical work in distance learning can be solved by developing teaching aids that use augmented reality, which projects two-dimensional or three-dimensional virtual objects into a natural environment in real-time. The article [16] describes the experience of creating an application based on AR technologies for teaching computer network devices, which contributes to a better understanding and motivation of students in mastering the study material.

Thus, research and literature review show that the introduction of digital and mobile technologies into the learning process is becoming more relevant since they can complement and create a high-quality symbiosis with traditional teaching methods. Such combinations help to increase the efficiency of the educational process.

The usage of computer science (CS) is becoming much more prevalent in society today. Especially in today's digital generation, gamification has become a popular tactic to encourage specific behaviors and increase motivation and engagement. Some platforms enable educators to use gaming technology to develop learning environments for students. Classcraft is one of the many examples of how technology can be used in classrooms to engage students and facilitate exciting, engaging, and exciting lessons. The results presented in this study suggest that students' engagement and attitudes toward programming have been positively affected. 
On the contrary, students' academic performance was not affected at a statistically significant level. The paper reflects the experience of students' interaction with plenty of educational gamification tools. Their study showed a positive effect on engagement and lessons' interest though the academic performance was not changed significantly [17].

Karakose et al. [18] investigate mobile technologies and other innovations in education from the opposite side. The authors surveyed one hundred seventy-six Greece primary and secondary teachers. The findings revealed why many of them are hesitant to adopt new technologies. The most common of them are technological equipment, and another reason is unfamiliarity with learning objects and simulation tools.

The importance of flexibility and readiness to unexpected cases and situations is highlighted in another work by Karakose et al. [19]. The authors have investigated many publications made during the pandemic and have developed thematic and methodological recommendations for sustainable research, especially among management, leadership, and administration.

Papadakis [20] analyzed the current use of mobile technology for STEM. The author reveals the high performance of the approach, and it is shown that it develops students' creative thinking and increases involvement and perception.

Despite all the advantages that the use and implementation of new technologies bring into the learning process, this approach also has several disadvantages. They cannot be ignored, especially for young minds with a fragile psyche. This question is studied in work presented by Buchner et al. [21]. The authors aimed to analyze the impact of AR on cognitive load, especially during the learning process. They found that the $\mathrm{AR}$ is relatively moderate regarding mental processes. Applications' design rather than the technology itself causes the increase in the consumption of the brain's resources. Thus, design principles in terms of augmented reality can control the performance of the application and its common perception.

The authors of [22] cite the experience of Russian higher education institutions. They look at mobile learning tools from the design, formation, and legal sides. In their opinion, mobile devices and technologies make it possible almost to avoid the organizational problems inherent in traditional education without losing their practical significance. Moreover, they allow avoiding psychological barriers and have unlimited access. However, such practices' implementation, regulation, and development are fraught with legal, organizational, and technical difficulties. It is also noted that the educational program should be tailored to the needs and interests of the students.

The use of the m-learning approach is also discussed by Saikat et al. [23]. The authors conducted a study of twenty-two articles on the use of mobile technology during the pandemic. They emphasize the importance and the high potential of the technology, although implementing all the necessary functionality still takes time. Paramount is the approach's safety, which is provided due to the possibility of remote interaction.

In [24], the authors note that there is still no clear definition of non-formal learning tools despite the new trend and increased applications. Moreover, although informal learning is more effective than formal, more precise characteristics and criteria are required for sustainable development. One of the tips for developing more effective mobile learning systems is to form a learning path that can be individually tailored to the needs, interests, and preferences. 
Most of the authors still consider mobile technologies an opportunity rather than a disadvantage and see great potential in them. However, like any product/direction, mobile learning is still at the stage of formation, when each developer has his/her vision and approach to development. In this regard, there is no theoretical basis, and as a result, the ground for assessing the product's effectiveness is in isolation from the user experience. Therefore, even though mobile technologies in education allow users/ students to get a richer experience, consider complex processes, study the material repeatedly and independently, after all, this method still requires specific improvements and the introduction of rules.

\section{Methodology}

Initially, the project was dedicated to using a mobile application to study physics in high school. Tasks from the program and the corresponding laboratory work were chosen for this purpose. All work on the project consisted of the following stages:

1. Gathering information, researching the experience of colleagues.

2. Development of requirements for the project.

3. Implementation of the project.

4. Development of a questionnaire.

5. Mailing the application and conducting a survey.

6. Processing of the survey results.

7. Summing up.

A quantitative analysis was used during the work, namely, a survey among application users. It was necessary to assess the benefits, usability of the program, and future improvements and draw a general picture of the introduction of mobile technologies into the educational process. The survey was chosen due to the project's original purpose; it was created for students, and thus they are the primary judge for evaluating its benefits. The questionnaire consists of questions on various aspects of the software: interface, usability, and the complexity of using the program. The questions were compiled based on Nielsen questionnaires, taken as valid.

\section{$4 \quad$ Instruments}

The application properties have become essential for the selection of development tools. The app must be compatible with Android and iOS devices and work in AR mode. The simplest solution was to use the Unity game engine, and the development of the project was carried out inside the Unity engine. The choice is justified by the authors' experience in this environment and a wide range of different functions and compatibility of various additional modules, including those providing augmented reality operation. In addition, it is also an advantage that Unity can be assembled for a wide range of different devices, both mobile and TV.

Another advantage of the environment is the interface's ease of use and customization of the workspace. Continuous software update allows you to create up-to-date 
applications to implement various frameworks. In addition, the authors have extensive experience with this environment. The Unity interface is user-friendly and straightforward, while it has many different tools, features, and parameters.

The C\# programming language is used to write code inside scenes. It is a high-level object-oriented programming language supported by the Unity framework. It allows you to customize all elements within scenes, define their behavior and interaction.

Also, the engine differs in its implementation of physics. This is made possible by NVIDIA's PhysX physics engine. In our case, this is especially important since we are implementing an imitation of physical processes. The engine and the programming language have excellent up-to-date documentation and community, improving and speeding up the development process.

To add functionality that works in augmented reality, the EasyAR library was chosen. It has many different functions, supports marker and markerless modes of operation. It is also possible to recognize several targets simultaneously, track planes.

\section{Implementation}

Before starting work on the project, it was necessary to determine the development methodology. As a result, it was decided to use Agile since it allows you to work efficiently and flexibly due to making changes directly during the development process itself. To begin with, the whole procedure was divided into the following stages:

1. Analysis of the market and analogs to identify current trends.

2. Development of general application requirements.

3. Design of the necessary 3D models, selection of development tools.

4. Project prototyping.

5. Application development.

The developed application is a physics study program that operates in augmented reality mode and allows users to switch between three different interface languages: Kazakh, Russian, English. The developers analyzed similar projects to study the main trends in developing such educational projects to implement the application. In addition, according to the project topic, the following requirements were identified: realistic equipment, correct imitation of physical processes. In Figure 1, you can see a model of technical equipment using the example of a lamp.

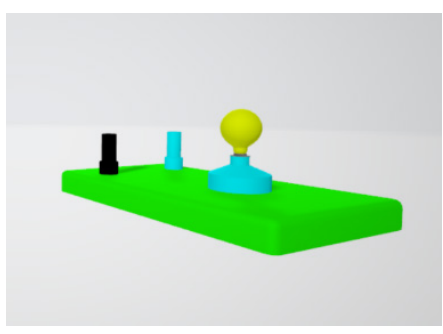

a) in a view mode

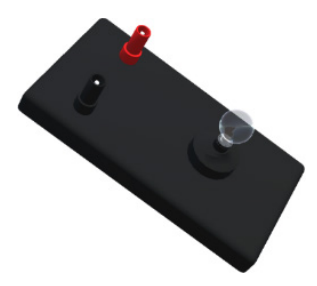

b) in the application

Fig. 1. 3D model of a lamp 
The next step was prototyping the user interface. Figure 2 shows the main menu prototype, and Figure 3 demonstrates its implementation in the application.

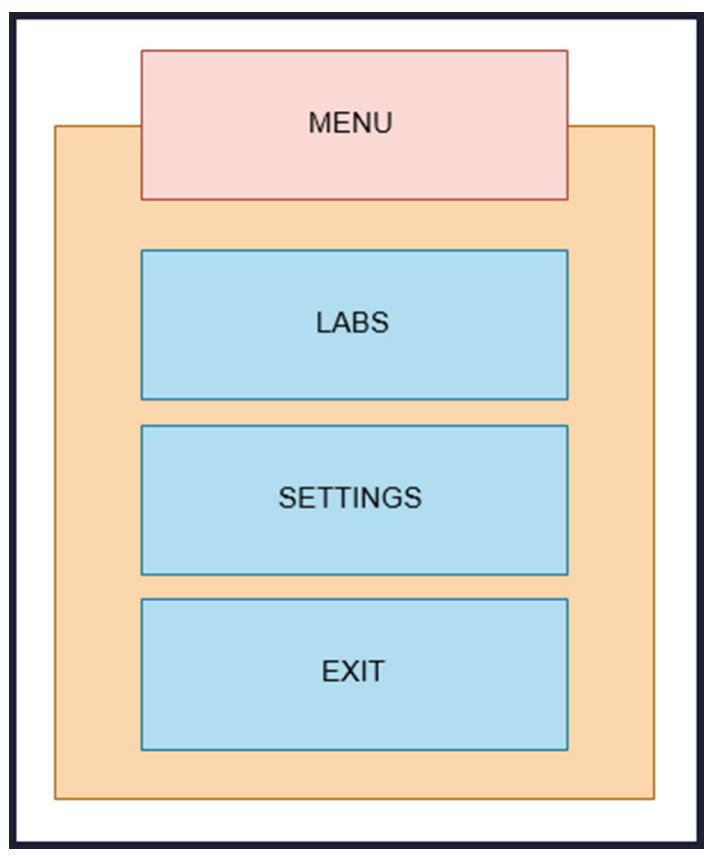

Fig. 2. Main menu prototype

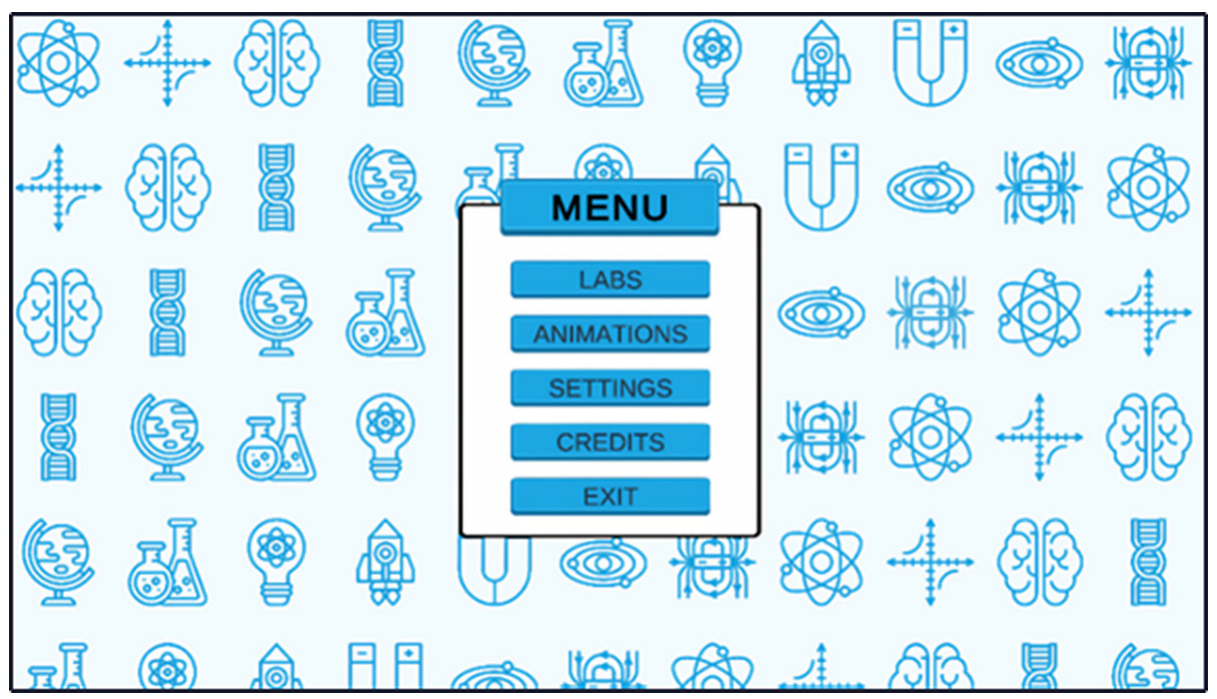

Fig. 3. Main menu 
In addition to prototyping the main menu, a prototype of scenes with virtual laboratories was also created. Figure 4 shows a screenshot of the interface. The templates allowed us to determine the optimal arrangement of interface elements, making the application's user experience more convenient. This was an essential criterion since the scenes with labs contain a large amount of text information to be displayed correctly.

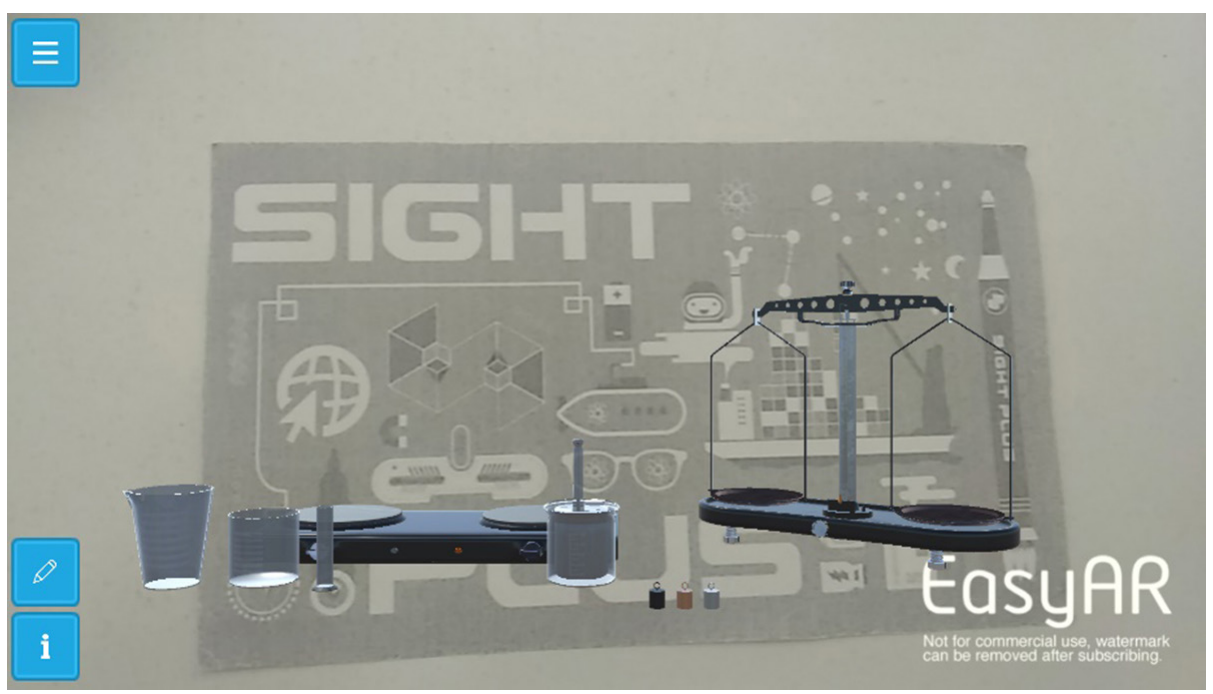

Fig. 4. Scene screenshot

Each scene has two buttons, "Assignment" "Data," so students can efficiently perform the task independently. The first button allows finding out the order of the work and the general requirements, and the "Data" button allows entering the received data necessary for calculations. This simplifies the work with the application since it does not need to use additional resources: paper, pens, or a text editor. In Figure 5, you can see the task in the scene, which describes the goal of the work, the equipment used in it, and the experiment's procedure. In case there are several tasks, there are buttons in the scene to switch between them. 


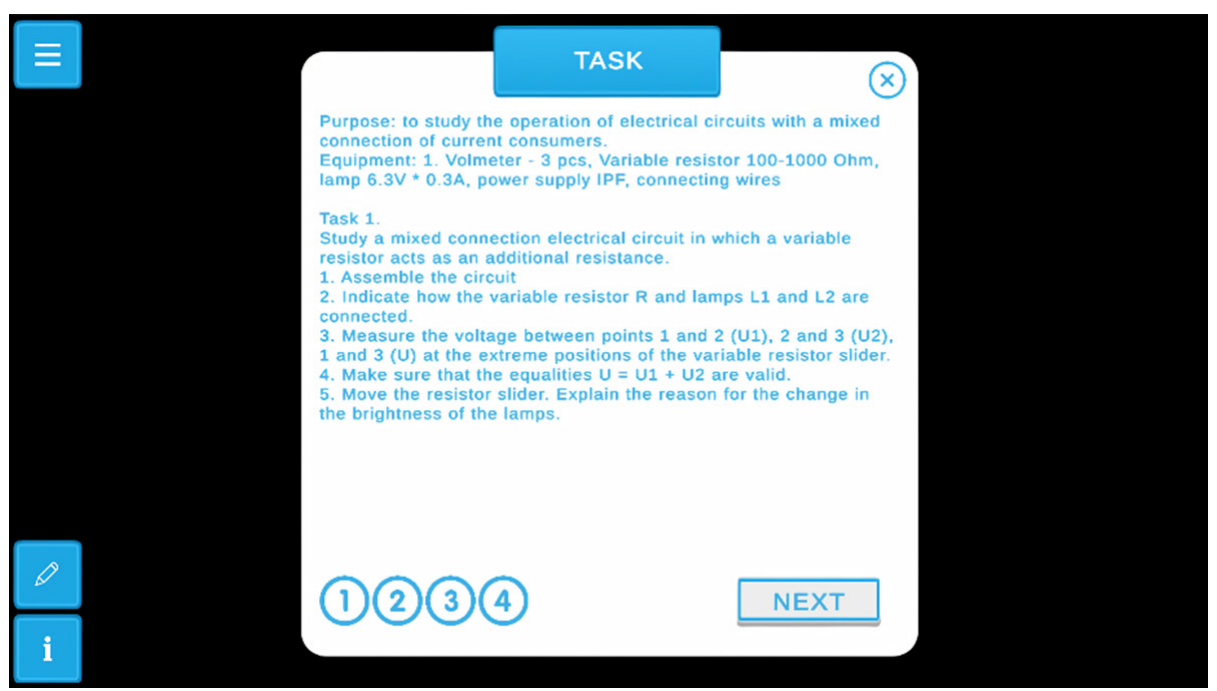

Fig. 5. Interface inside the scene with a description of the task

Figure 6 shows a class diagram of one of the application scenes. It consists of various classes to ensure the correct operation of the laboratory practice. To provide the work in three languages, the LocalizationController class is used, in which the data is translated.

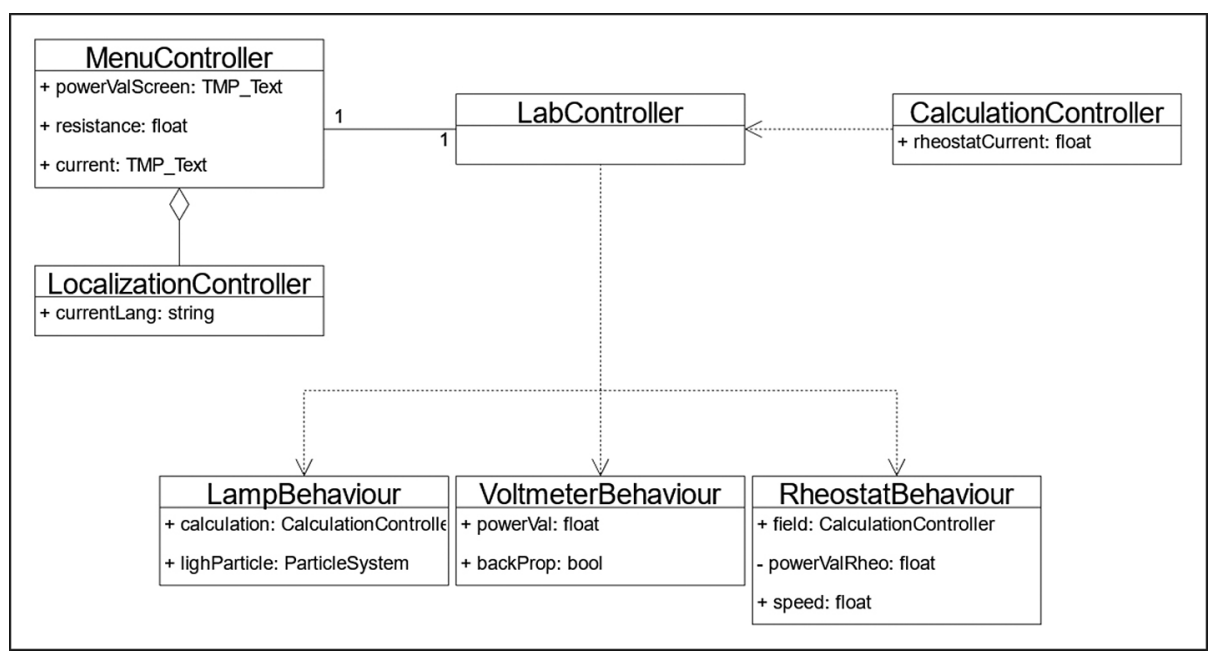

Fig. 6. Class diagram of the lab "Studying a mixed connection of conductors"

The CalculationController class is used to calculate various parameters studied while working on an assignment. The classes LampBehaviour, VoltmeterBehavoir RheostatBehaviour are responsible for the behavior of devices used in the lab: lamps, voltmeter, 
and rheostat. The LabController class is needed to monitor the operation of the system and its correct flow.

\section{Results and evaluation}

At the end of the 2020-2021 academic year, after completing a physics course in high school, within which the developed application was used, the authors, together with the teacher, surveyed students about the effectiveness of such training systems in general and this application in particular. The survey involved two classes of 34 schoolchildren, and they were asked the following questions:

1. Rate the degree of realism of the experiments performed (from 1 to 5).

2. Rate the degree of ease of use of the application (from 1 to 5).

3. Are the developed virtual experiments practical as an additional and convenient source of knowledge on the relevant topic?

4. Do the developed applications contribute to a clearer understanding of the material than after reading the information in a book?

5. Do such virtual experiments contribute to an increase in interest in physics classes?

The answer options for questions 3 to 5 are as follows: no, rather no, do not know, somewhat yes, yes. The survey results are shown in Table 1.

Table 1. Student survey results

\begin{tabular}{|l|c|c|c|c|c|}
\hline $\begin{array}{c}\text { Questions/ } \\
\text { Answers }\end{array}$ & $\begin{array}{c}\mathbf{1} \\
\text { No }\end{array}$ & $\begin{array}{c}\mathbf{2} \\
\text { Rather No }\end{array}$ & $\begin{array}{c}\mathbf{3} \\
\text { Do Not Know }\end{array}$ & $\begin{array}{c}\mathbf{4} \\
\text { Rather Yes }\end{array}$ & $\begin{array}{c}\mathbf{5} \\
\text { Yes }\end{array}$ \\
\hline Question 1 & & $6 \%$ & $9 \%$ & $45 \%$ & $40 \%$ \\
\hline Question 2 & & & $5 \%$ & $45 \%$ & $50 \%$ \\
\hline Question 3 & & & & $18 \%$ & $82 \%$ \\
\hline Question 4 & & & & $10 \%$ & $90 \%$ \\
\hline Question 5 & & & & $12 \%$ & $88 \%$ \\
\hline
\end{tabular}

The survey results show that the developed application is a convenient and effective additional source of knowledge. Also, when it is not possible to conduct actual physical experiments or within distance learning, the mobile application is an effective teaching tool that allows students to expand and consolidate the knowledge gained in the classroom and increase interest in the course. At the same time, the use of augmented reality makes it possible to make learning conduct training in a more exciting form.

Based on the obtained data, we can unequivocally conclude that using the application for conducting virtual experiments is an effective and exciting tool for involving students in the study of the material: 30 people answered that they consider the project as such, 4-that it is more likely yes than no.

However, the realism of the experiments demonstrated caused rather unpleasant sensations for two students, three students were unable to decide, but the application and the experiments within it proved quite realistic for 29 students. 
In the case of ease of interaction with the application, two students answered that they were at a loss to answer, but 32 students found it easy.

When asked about the application's relevance, the students' opinion was also somewhat approving: 28 students answered affirmatively, while six said that it was instead yes.

It can also be seen from the results that visualization of physical processes makes them easier to understand, so 31 students answered that the program made it easier to understand the information presented in the textbook. Three students also tend to consider the application clearer than not.

The scores obtained generally demonstrate a positive perception of the application and an eagerness to incorporate it into the learning process.

The work results confirm the initial hypothesis about the benefits of using new technologies in the educational process, in this case, studying physics in high school. The development of the project and the selection of materials for implementation demonstrated the relevance, and as a result, the usefulness, which was expressed in the survey results. Another important outcome of the research is the importance of target functionality and AR design itself because effective use of such applications necessitates proper instruction and descriptions for users within the application.

Another significant result of the study is the need to expand the questionnaire to cover all the characteristics of the application and take into account the model of the device on which the application is being tested since this affects the application's performance.

AR design is a relatively new field that is yet to be studied, and proper information demonstration with no redundancy for the user's consciousness is the most important goal, especially regarding young people.

Another challenge of this project is the selection of respondents and the questions presented. Due to the specific audience- - high school students, collecting sufficiently accurate information that will reflect the students' thoughts is quite challenging.

For some reason, this study has some limitations. A more honest and thorough evaluation necessitates a significant increase in the number of questions, including more factors to evaluate the application. It is also essential to expand the group of people who answer the questions and possibly change the order of the study to get a complete picture. For example, it might be helpful to divide the participants into two groups and, for some time, let one of them use the application and the other not, and as a result, to compare their academic performance and identify the dependencies of their grades on the study mode.

In addition, a record of user interaction with the application may be required to track whether the user behaves expectedly, how comfortable it is for him/her, and how honest the answers to the questions about evaluating the application are.

\section{Conclusion}

The work on this project shed light on the use of mobile technologies in the educational process and the difficulties and advantages of this method. Since its inception and throughout its evolution, information technology has had a profound impact on all aspects of our lives, including education. Moreover, the forced transition of educational 
institutions to distance learning due to the coronavirus pandemic opened up new prospects for introducing ICT in education. Mobile devices are now regarded as just a means of communication and interaction between students and teachers. They serve as an indispensable teaching tool, contributing to the overall development of the educational process and introducing innovative teaching methods.

An indispensable condition for introducing mobile technologies into the educational process is developing appropriate software, for example, virtual laboratories. This article shows the process of developing a mobile application for the multilingual educational platform (Kazakh, Russian, English) for distance learning of physics in higher and secondary educational institutions using augmented reality technology. The authors plan to expand the application's functionality and increase the number of topics and tasks in the future.

Studying the available world experience and the forced acceleration due to the 2020 pandemic, the authors established the following mandatory elements of modern mobile learning systems. First, it is essential to meet the criteria for sustainable development. Sustainable development means meeting current needs without prejudice to the future. The use of the software fully meets this criterion. Working in a mobile app reduces the cost of manufacturing equipment, requires less energy, and positively impacts the educational experience. Another term in sustainability is no harm for human perception. The information contained within the application must clarify and simplify understanding of complex phenomena by utilizing technologies in the simplest way possible, as defined by AR design principles.

Secondly, mobile learning allows you to reach many students while encouraging their independence and involvement in the process.

So, it is imperative to adapt to different platforms and technical specifications. Taking this into account will allow you to create applications that various users can use without affecting the program's operation and users' experience.

\section{Acknowledgment}

This research was funded by the Science Committee of the Ministry of Education and Science of the Republic of Kazakhstan (Grant No. AP 09563181).

\section{$9 \quad$ References}

[1] Statista. (2021). Worldwide mobile education app downloads by platform from 1 st quarter 2017 to 1 st quarter 2020. Retrieved from https://www.statista.com/statistics/1128262/ mobile-education-app-downloads-worldwide-platforms-millions/

[2] Davis, C. R., Grooms, J., Ortega, A., Rubalcaba, J. A.-A., \& Vargas, E. (2021). Distance Learning and Parental Mental Health During COVID-19. Educational Researcher, 50(1), 61-64. https://doi.org/10.3102/0013189X20978806

[3] Armstrong-Mensah, E., Ramsey-White, K., Yankey, B., \& Self-Brown, S. (2020). COVID-19 and distance learning: Effects on Georgia State University public health students. Frontiers in Public Health, 8, 547. https://doi.org/10.3389/fpubh.2020.576227

[4] https://newzoo.com/insights/rankings/top-countries-by-smartphone-penetration-and-users/ 
[5] Potapova, M. V. Laboratory and creative works conduction methods using mobile devices. Concept Vol. 7, Available: https://cyberleninka.ru/article/n/metodika-provedeniya-laboratornyh-i-tvorcheskih-rabot-s-primeneniem-mobilnyh-gadzhetov [Accessed: 23.08.2021].

[6] Merchant, G. (2012). Mobile practices in everyday life: Popular digital technologies and schooling revisited. British Journal of Educational Technology Special Issue: Social Networking and Mobile Learning, 43(5), 770-782. https://doi.org/10.1111/j.1467-8535.2012.01352.x

[7] Acheamponga, E., \& Agyemang, F. G. (2021). Enhancing academic library services provision in the distance learning environment with mobile technologies. The Journal of Academic Librarianship, 47(1). https://doi.org/10.1016/j.acalib.2020.102279

[8] Bernacki, M. L., Greene, J. A., \& Crompton, H. (2020). Mobile technology, learning, and achievement: Advances in understanding and measuring the role of mobile technology in education. Contemporary Educational Psychology, 60. https://doi.org/10.1016/j. cedpsych.2019.101827

[9] Liashenko, O. I., \& Tereshchuk, S. I. (2019). Using the mobile technology plickers in the process of learning physics. Information Technologies and Learning Tools, 70(2), 59-70. https://doi.org/10.33407/itlt.v70i2.2738

[10] Salnyk, I. V. (2019). Mobile devices and modern education software in learning physics in secondary school. Information Technologies and Learning Tools, 73(5), 1-14. https://doi. org/10.33407/itlt.v73i5.2918

[11] Fojtik, R. (2014). Mobile Technologies Education. 3rd Cyprus International Conference on Educational Research, 143, 342-346. https://doi.org/10.1016/j.sbspro.2014.07.417

[12] Voštinár, P. (2018). Creating mobile apps for teaching. In Proc. of 12th International Technology, Education and Development Conference, 811-816. https://doi.org/10.21125/ inted.2018.1156

[13] Rochmah, I. N., \& Hwang, W. Y. (2021). Students' acceptance toward the use of mobile learning infractions. Journal of Physics: Conference Series, 1810(1), IOP Publishing. https:// doi.org/10.1088/1742-6596/1810/1/012037

[14] Tavares, R., Vieira, R., \& Pedro, L. (2017). Preliminary proposal of a conceptual educational data mining framework for science education: Scientific competences development and self-regulated learning. In Proc. of the 2017 International Symposium on Computers in Education (SIIE), 1-6. https://doi.org/10.1109/SIIE.2017.8259644

[15] Hamzah, M. L., Ambiyar, A., Rizal, F., Simatupang, W., Irfan, D., \& Refdinal, R. (2021). Development of augmented reality application for learning computer network device. International Journal of Interactive Mobile Technologies, 15(12). https://doi.org/10.3991/ijim. v15i12.21993

[16] Papadakis, S., \& Kalogiannakis, M. (2019). Evaluating the effectiveness of a game-based learning approach in modifying students' behavioural outcomes and competence, in an introductory programming course. A case study in Greece. International Journal of Teaching and Case Studies, 10(3), 235-250. https://doi.org/10.1504/IJTCS.2019.10024369

[17] Poultsakis, S., Papadakis, S., Kalogiannakis, M., \& Psycharis, S. (2021). The management of digital learning objects of natural sciences and digital experiment simulation tools by teachers. Advances in Mobile Learning Educational Research, 1(2), 58-71. https://doi. org/10.25082/AMLER.2021.02.002

[18] Karakose, T., Yirci, R., Papadakis, S., Ozdemir, T. Y., Demirkol, M., \& Polat, H. (2021). Science mapping of the global knowledge base on management, leadership, and administration related to COVID-19 for promoting the sustainability of scientific research. Sustainability, 13, 9631. https://doi.org/10.3390/su13179631 
[19] Karakose, T., Yirci, R., \& Papadakis, S. (2021). Exploring the interrelationship between COVID-19 Phobia, work-family conflict, family-work conflict, and life satisfaction among school administrators for advancing sustainable management. Sustainability, 13(15), 8654. https://doi.org/10.3390/su13158654

[20] Papadakis, S. (2021). Advances in Mobile Learning Educational Research (AMLER): Mobile learning as an educational reform. Advances in Mobile Learning Educational Research, 1(1), 1-4. https://doi.org/10.25082/AMLER.2021.01.001

[21] Buchner, J., Buntins, K., \& Kerres, M. (2021). The impact of augmented reality on cognitive load and performance: A systematic review. Journal of Computer Assisted Learning, 1-19. https://doi.org/10.1111/jcal.12617

[22] Toktarova, V. I., \& Shpak, A. E. (2021). Mobile Learning: Tools and Services, Functions and Opportunities. Proceedings of INTCESS, 2021 (8th). https://doi.org/10.51508/ intcess.2021129

[23] Saikat, S., Dhillon, J. S., Wan Ahmad, W. F., \& Jamaluddin, R. (2021). A systematic review of the benefits and challenges of mobile learning during the COVID-19 pandemic. Education Sciences, 11(9), 459. https://doi.org/10.3390/educsci11090459

[24] Viberg, O., Andersson, A., \& Wiklund, M. (2021). Designing for sustainable mobile learning-re-evaluating the concepts "formal" and "informal." Interactive Learning Environments, 29(1), 130-141. https://doi.org/10.1080/10494820.2018.1548488

\section{Authors}

Yevgeniya A. Daineko is a vice-rector on scientific and international affairs at International Information Technology University, $\mathrm{PhD}$, associate-professor. She has a rich experience in the field of educational applications for students using virtual reality and augmented reality. Sphere of her scientific interest lies in digitalization of the traditional educational systems using modern approaches.

Dana D. Tsoy is an engineer of Mixed Reality Laboratory at International Information Technology University, Master of Technology. She works in the field of software development of applications using virtual reality, augmented reality.

Aigerim M. Seitnur is a lecturer at International Information Technology University, Master of Technology. She works in the field of animation of different processes including physics. Also she is experienced in creation of math models of different phenomenon.

Madina T. Ipalakova is a director of scientific department at International Information Technology University, $\mathrm{PhD}$, associate-professor. She has a rich experience in the field of educational applications for students using virtual reality and augmented reality. Sphere of her scientific interest lies within appliance of these modern tools in education.

Article submitted 2021-09-17. Resubmitted 2021-12-22. Final acceptance 2021-12-28. Final version published as submitted by the authors. 